\title{
Gender Differences in Identities and Their Sociostructural \\ Correlates: How Gendered Lives Shape Parental and Work Identities
}

\section{Ruth Gaunt ${ }^{1,2}$ and Jacqueline Scott ${ }^{1}$}

\begin{abstract}
This study draws on identity theory to explore parental and work identities. It examined gender differences in identities, as well as the moderating role of gender in the effects of individuals' sociostructural characteristics. A sample of I 48 couples with young children completed extensive questionnaires. As hypothesized, couples' paid-work strategy moderated gender differences in the salience and centrality of parental and work identities. Whereas significant differences in identities were found between stay-at-home mothers and their breadwinning husbands, no differences were found among dual-earner couples. Moreover, men's work identity centrality increased when they had more and younger children, whereas women's work identity centrality decreased. Finally, men's parental identity centrality increased with their income, whereas women's parental identity centrality decreased the more they earned. These findings attest to the importance of examining differences within as well as between genders, by taking into account the interactive effects of gender with other sociostructural characteristics.
\end{abstract}

\section{Keywords}

gender differences, parental identity, work and family, self-concept

\footnotetext{
'University of Cambridge, Cambridge, UK

2University of Lincoln, Lincoln, UK
}

\section{Corresponding Author:}

Ruth Gaunt, School of Psychology, University of Lincoln, Brayford Pool, Lincoln LN6 7TS, UK. Email: rgaunt@lincoln.ac.uk 
For the majority of people, being a man or a woman means leading a very different life, especially after entering parenthood (Baxter, Hewitt, \& Haynes, 2008; Scott, Dex, \& Plagnol, 2012). Men and women internalize gendered social expectations and develop self-identities that reflect them (Thoits, 1991; Wiley, 1991). Both the structure of the self-concept and the meanings attached to various identities (e.g., parent, worker) may thus vary depending on gender (Stryker, 1987; Thoits, 1991).

Investigating gender differences in identities is of major importance for a better understanding of barriers to greater gender equality. Identities act as motivators that guide individuals' choices and behaviors (Stryker, 2008), and may therefore provide the link between societal forces and individuals' everyday behavioral choices (Burke \& Stets, 2009). More specifically, gendered parental and work-related identities guide couples' allocation of family responsibilities and account for gender inequalities in parents' involvement in child care (Fox \& Bruce, 2001; Gaunt \& Scott, 2014; Goldberg, 2015), which in turn disadvantage women in the workforce (Gershuny, 2004). Given the implications of identities on individual lives, it is crucial to closely examine differences in men's and women's identities and their determinants.

This study draws on identity theory (Burke \& Stets, 2009; Stets \& Serpe, 2013; Stryker, 2008) to explore women's and men's parental and workrelated identities. Based on a sample of British couples with young children, it seeks to determine whether there are gender differences in identities and whether gender moderates the associations between identities and sociostructural characteristics. Previous findings regarding gender differences in the salience of parental and work identities have yielded mixed evidence (e.g., Cinamon \& Rich, 2002; Scott \& Alwin, 1989; Snir, Harpaz, \& Ben-Baruch, 2009). To account for these inconsistencies, couples' paid-work strategies are considered as a moderator. It is argued that gender differences in identities characterize traditional couples but are eliminated when spouses lead more similar lives.

Moreover, while individuals' identities are shaped through life experiences and embedded within larger social structures (Stryker, Serpe, \& Hunt, 2005), little is known about the ways in which the sociostructural characteristics that affect men's and women's identities differ (Aryee \& Luk, 1996; Bielby \& Bielby, 1989). The current study suggests that gender moderates the associations between individuals' sociostructural characteristics and the importance of parental and work identities to their self-concept.

Our hypotheses were tested on a convenience sample of British couples from the Cambridgeshire area. As in other Western countries, the recent decades have witnessed dramatic rise in British women's employment rates (Scott, Dex, \& Joshi, 2008). The United Kingdom is characterized, however, 
by a dominant male-breadwinner/part-time female-caregiver ideological model, and the significant increase in mothers' employment has been largely concentrated in part-time jobs (Kanji, 2011). Therefore, while the United Kingdom has one of the highest employment rates in Europe for mothers of preschool children, it also has one of the lowest rates of maternal full-time employment (Kanji, 2011). This unique combination results in part from the lack of state-funded child care provision for small children, the short- and long-term costs of women's career breaks and the social disapproval of fulltime employment for mothers (Himmelweit \& Sigala, 2004). This gendered context thus seems particularly suitable for examining women's and men's identities and their sociostructural correlates.

\section{Identity Theory}

According to Identity Theory, role identities are the meanings applied to the self in a social role (Stets \& Serpe, 2013; Stryker, 1980, 2008). Whereas roles are external, and linked to social positions within the social structure, identities are internal, and consist of internalized meanings and expectations associated with a role (Stryker \& Burke, 2000). Identities are therefore social products, which are formed in particular situations and circumstances and maintained through interactions with others (Burke \& Stets, 2009).

This theory suggests that individuals have many identities that are hierarchically organized in terms of their salience (Stryker, 1980) and psychological centrality (Rosenberg, 1979). Identity salience is defined as the probability that an identity will be invoked across a variety of situations (Stryker, 1980). Identity centrality is the importance individuals attach to an identity (Rosenberg, 1979; see also identity prominence, McCall \& Simmons, 1978). Whereas identity salience does not require self-conscious or self-aware actors, identity centrality refers to individuals' own subjective judgments of the importance of each of their identities and therefore assumes a level of self-awareness (Stryker \& Serpe, 1994).

An important premise of identity theory is that the salience and centrality of identities are linked to individuals' circumstances and situational characteristics (Merolla, Serpe, Stryker, \& Schultz, 2012). While individuals develop their own self-definitions, these are influenced by the realities of the social structures within which they are embedded (Stets \& Serpe, 2013). In particular, large (e.g., gender, socioeconomic status), intermediate (e.g., organizations), and proximate (e.g., family) social structures affect the likelihood that the individuals located within them will develop particular kinds of selves (Stryker et al., 2005). This theory further assumes bidirectional relationships between identities and individual circumstances, such that identities are 
shaped by certain social circumstances and in turn guide behavioral choices that affect these circumstances. Thus, for example, full-time employment is likely to enhance professional identity, and a new mother's central professional identity is likely to guide her choice to continue to commit to full-time employment. Nevertheless, some social structures are less prone to individual choice (e.g., gender, age of the children). While acknowledging this bidirectional nature of relationships, the present study focuses on the role of social structures in the salience and centrality of men's and women's identities.

\section{Gender Differences in Identities}

When considering the social structural characteristics that affect the salience and centrality of identities, the gendered sociocultural context within which men and women function must be taken into account (Scott et al., 2012; Stone, 2007). Despite the considerable changes in women's work patterns and the gradual increase in men's participation in the home over the past few decades (McGill, 2014; Sullivan, 2006), women and men still assume main responsibilities for their traditional roles as caregivers and breadwinners, respectively (Bianchi \& Milkie, 2010; Kan, Sullivan, \& Gershuny, 2011).

Identity theory suggests that gender operates as a "master status" which often overrides other characteristics of the person and affects the salience and meanings of role identities (Stryker, 1987; Thoits, 1991). A number of studies have indeed shown that women's parental identities tend to be more salient than men's (Cinamon \& Rich, 2002; Scott \& Alwin, 1989), and a few studies have found in addition that men's work-related identities tend to be more salient than women's (e.g., Aryee \& Luk, 1996; Bielby \& Bielby, 1989; Maurer, Pleck, \& Rane, 2001). However, the evidence for such gender differences is mixed and several studies have failed to document them (e.g., Friedman \& Weissbrod, 2005; Snir et al., 2009; Thoits, 1992). It is plausible that the relatively large variability in women's work patterns accounts for some of these inconsistencies (e.g., Cinamon \& Rich, 2002; Gaunt \& Benjamin, 2007). Whereas the vast majority of men work full time (Sayer \& Gornick, 2011), women, and especially mothers of preschool children, tend to exhibit great variability in work patterns, ranging from no paid work, through part-time jobs to full-time work outside the home (Harkness, 2008). These various work patterns are likely to be linked to the relative importance of parental and work identities to the self-concept, such that gender differences in identities are less likely among dual earners, where both spouses work full time. Presumably, such differences should be more substantial among traditional couples consisting of a housewife and a male breadwinner, 
and may be reduced among modified traditional couples where the wife works part time.

\section{Gender Differences in the Effects of Sociostructural Characteristics}

Beyond these gender differences in the salience of work and family identities, gender as a master status may also change the meanings of identities (Stryker, 1987; Thoits, 1991). Given that identities are internalized meanings produced in a certain social environment, a gendered environment implies that different meanings are attached to work and parenting roles depending on gender (Wiley, 1991). In particular, the expectations associated with the position of a parent or a worker are different for men and women. Despite changes in social expectations in recent decades regarding fathers' involvement in child care (Adams, Walker, \& O'Connell, 2011; Wall \& Arnold, 2007), good fathering is still associated primarily with being a good worker and breadwinner, whereas good mothering is associated with providing care to young children (e.g., DeWitt, Cready, \& Seward, 2013; Gaunt, 2013; Wall, 2013). In this way, men's work and family identities are consistent and positively related to each other, whereas women's work and family identities are in conflict (Aryee \& Luk, 1996; Friedman \& Weissbrod, 2005; Hodges \& Park, 2013; Stone, 2007). Because of these different meanings, men's and women's parental and workrelated identities may be differentially linked to their social structural characteristics. In other words, gender may moderate the effects of other structural variables on identities (Aryee \& Luk, 1996; Bielby \& Bielby, 1989).

Conventional images of motherhood, in particular, still portray mothers as the irreplaceable main caretakers for babies and young children, and prescribe intensive, child-centered mothering (Adams et al., 2011; Stone, 2007; Wall, 2013). As women develop their self-identities as mothers, these social expectations are internalized and are likely to generate stronger associations between the presence of young children and the salience of women's parental identities than men's parental identities (Aryee \& Luk, 1996; Katz-Wise, Priess, \& Hyde, 2010). Moreover, these social images of intensive mothering increase the perceived conflict between motherhood and paid work (Friedman $\&$ Weissbrod, 2005; Stone, 2007) and result in the social disapproval of fulltime employment for mothers (Himmelweit \& Sigala, 2004; Wall, 2013). The presence of children (and the more and younger they are) should therefore be negatively associated with women's work identities but not with men's (Evertsson, 2013).

Conventional images of fatherhood, in contrast, are still largely focused on breadwinning rather than daily child care (Gregory \& Milner, 2011; 
Hodges \& Park, 2013). Although popular representations of "new fatherhood" include involvement in hands-on child care (Adams et al., 2011; Gregory \& Milner, 2011), fathers continue to be perceived as secondary caregivers and primary breadwinners (Adams et al., 2011; Hodges \& Park, 2013; Wall \& Arnold, 2007). Because of this perceived centrality of breadwinning to fathers' role, and the perceived conflict between paid work and mothers' role, earnings should be positively related to men's parental identities (Aryee \& Luk, 1996) but negatively related to women's parental identities.

\section{Aims and Hypotheses}

In light of the above reasoning, the present study explores gender differences in identities and their sociostructural correlates. It extends previous literature in several important ways. First, to account for the inconsistent findings regarding gender differences in the salience and centrality of work and parenting identities, the moderating role of couples' paid-work strategy is considered (Scott \& Plagnol, 2012). That is, gender differences are examined separately among traditional, modified traditional, and dualearner couples. Second, the moderating role of gender in the associations between structural characteristics and identities is explored. Because of the different meanings and expectations associated with the parent and worker roles for men and women, differential associations are expected between the presence of young children and the salience of parental and work identities depending on gender. Individuals' income is similarly expected to be differentially linked to men's and women's identities. Finally, the present study maintains the conceptual and empirical distinction between identity salience and psychological centrality. Although previous studies have tended to treat these concepts as synonymous, a few reports that maintained this distinction found that identity salience and centrality are two relatively independent dimensions of the self-structure and recommended that both should be incorporated into the research design (Stets \& Biga, 2003; Stryker \& Serpe, 1994).

Two sets of hypotheses were derived from the rationale presented above:

\section{(I) Gender differences in identities:}

Hypothesis 1a: Overall, it is hypothesized that women will have more salient and central parental identities than men, and men will have more salient and central work identities than women.

Hypothesis 1b: Couples' paid-work strategy is expected to moderate these effects, so that differences in identity salience and centrality will be found among traditional couples but not among dual earners. 
To test this hypothesis, we followed Scott and Plagnol's (2012) procedure and classified the couples in our sample into three strategy categories based on the spouses' weekly hours of paid work. "Traditional" couples consisted of a woman who does not work for pay and a man who works full time, "modified male breadwinner" couples consisted of a woman who works part time (less than 30 hours per week) and a man who works more hours than the woman, and "dual-earner" couples were those in which both spouses work 30 hours or more per week. We then conducted a series of mixed-model analyses of variance to examine moderation by paid-work strategy.

(II) Gender differences in the effects of children and income on identities:

Hypothesis 2a: Because of the differential social perceptions of motherhood and fatherhood discussed above, it is hypothesized that gender will moderate the effects of children on participants' work identities. That is, more children and a child's younger age will have negative effects on the salience and centrality of women's work identities, but will be unrelated to men's work identities.

Hypothesis 2b: It is further hypothesized that gender will moderate the effects of children on participants' parental identities. Specifically, more children and a child's younger age will be associated with more salient and central parental identities among women, but will be unrelated to men's parental identities.

Hypothesis 2c: Consistent with the reasoning discussed above, it is hypothesized that gender will moderate the effects of income on participants' parental identities. Whereas income is expected to correlate positively with men's parental identity, a negative correlation is hypothesized among women.

To examine these moderations by gender, we followed the methods developed by Hayes $(2012,2013)$ for evaluating moderation effects using the bootstrap procedure. Bootstrap resampling of the data provides estimates for the model paths and a confidence interval (CI) of these estimates. The analyses were conducted using Hayes's (2013) PROCESS macro (Model 1) with 1,000 bootstrap samples and bias-corrected CIs.

\section{Method}

\section{Participants}

One hundred and forty-eight married couples with children $(n=296)$ participated in the study as part of a larger research project on work and family. A 
convenience sample was recruited by research assistants through play groups, schools, and community centers in Cambridgeshire, the United Kingdom. Table 1 lists the demographic characteristics of the participants by gender. The men's ages ranged from 22 to $56(M=38, S D=6.70)$ and the women's ages ranged from 23 to $49(M=35, S D=5.78), t(1,145)=6.44, p<.001$. The couples represented a broad range of socioeconomic levels, with an overrepresentation of educated couples. Approximately $16 \%$ of the participants had not finished high school, but $64 \%$ of the men and $59 \%$ of the women had an academic degree, compared with $35 \%$ in the general population (Office for National Statistics, 2011). There were no gender differences in levels of education (Wilcoxon rank sum test $Z=.40, p=.68$ ). The men's work hours ranged from 0 to 85 hours per week $(M=44.93, S D=13.56)$; only $3 \%$ of the men did not work for pay, 7\% worked less than 30 hours per week, and $90 \%$ worked 30 hours or more per week. The women's work hours ranged from 0 to 72 hours per week $(M=17.88, S D=15.84)$ and closely reflected those of married mothers with preschool children in the general population $(M=$ 17.80, Harkness, 2008). Similar to the distribution found in the general population (Office for National Statistics, 2008), 31\% of the women in the sample did not work for pay, $40 \%$ worked less than 30 hours per week, and an additional $29 \%$ worked 30 hours or more. Overall, in the majority of the couples, the husband worked more hours than the wife, $t(1,143)=15.54, p<.001$, and had a higher income (Wilcoxon rank sum test $Z=8.28, p<.001$ ). The number of children per couple ranged from 1 to $5(M=2.01, S D=0.92)$. A total of $31 \%$ of the families had one child, $46 \%$ had two children, $17 \%$ had three children, and $6 \%$ had four or five children. The youngest child's age ranged from 1 to 6 years $(M=2.88, S D=1.77)$.

The couples in the sample were classified into three paid-work strategy categories following Scott and Plagnol's (2012) procedure. Forty-five couples were classified as "traditional," 53 couples were classified as "modified male breadwinner" couples, and 38 couples were classified as "dual-earner" couples. The remaining "female breadwinner" category, where the woman worked more than the man, consisted of nine couples only and was therefore not included in the analysis of moderation by strategy.

\section{Measures}

Identity Salience. To measure the salience of the participants' identities, a "Who am I?" open-ended question asked participants to define themselves in terms of their relationships and roles. This measure (and its variant "the Twenty-Statements Test"; Kuhn \& McPartland, 1954) has been widely used to explore gender and cultural differences in self-concept (Dhawan, 
Table I. The Demographic Characteristics of the Participants.

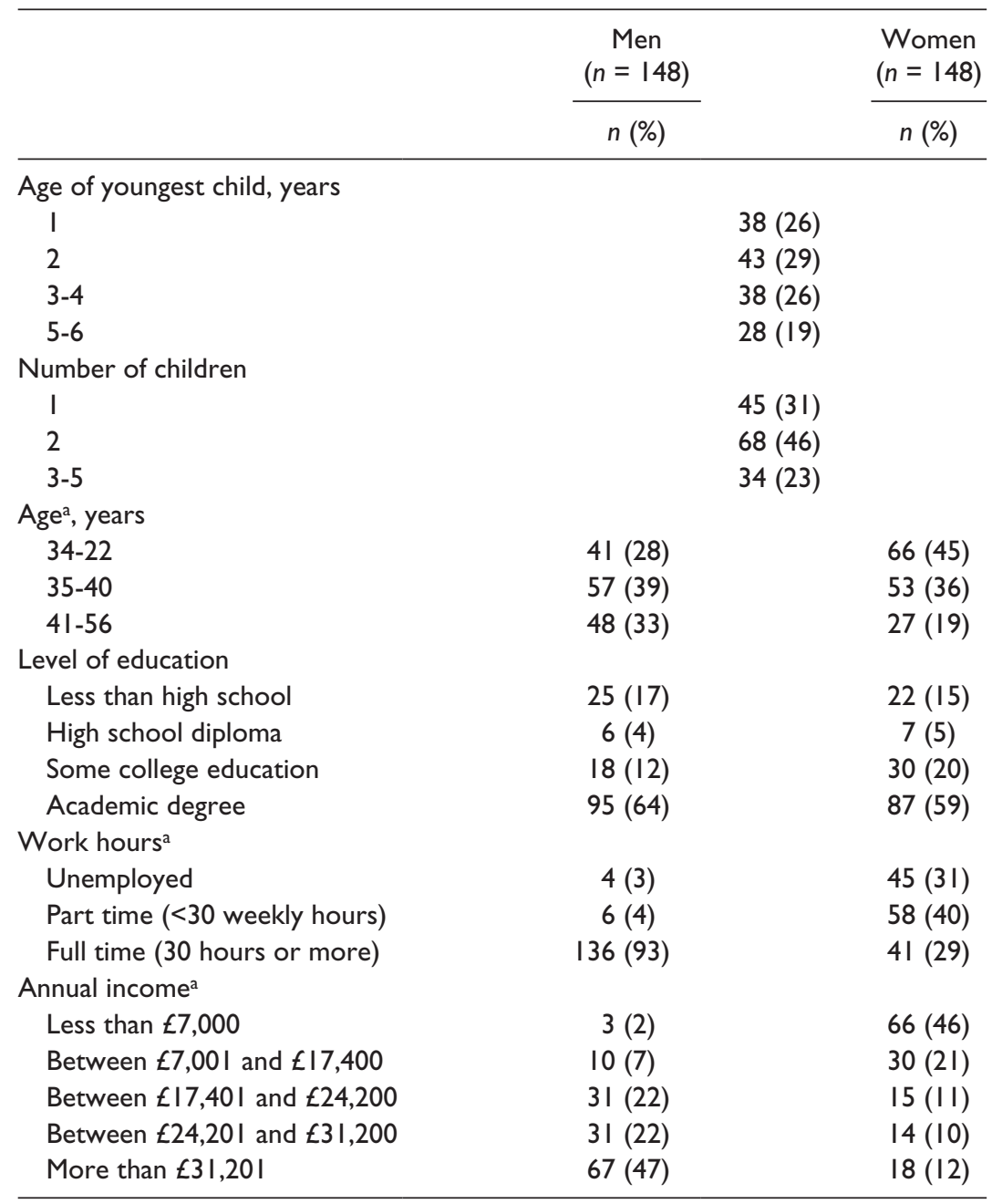

a Significant gender differences were found.

Roseman, Naidu, Thapa, \& Rettek, 1995; Eaton \& Louw, 2000; Kanagawa, Cross, \& Markus, 2001; Mackie, 1983), as well as its relations to self-esteem and well-being (Lay \& Verkuyten, 1999; Rentsch \& Heffner, 1992; Thoits, 1992). This measure required participants to complete 10 statements about themselves, starting with the words "I am ... " The instructions read: "In the space provided below, please try to describe yourself in terms of your 
relationships and social roles. Please write down your answers just as they come to your mind, don't attempt to explain or organize them." The first author and a research assistant independently coded the responses while being unaware of the participants' other data. Each response was classified as a parental, work-related, or other identity. Intercoder agreement was very high (97\%; kappa statistic .99) and discrepancies in judgments were discussed and resolved. Based on the assumption that the order of spontaneous recall responses reflects mental availability (Mussweiler \& Bodenhausen, 2002), participants' parental and work-related responses were then assigned numbers to indicate their mental availability on a scale from 10 (the identity was mentioned first), through 9 (mentioned second), down to 1 (mentioned 10th). An identity that was not mentioned by the participant was coded 0 . Although the participants mentioned a wide range of identities, subsequent analyses focused on parental and work-related identity salience scores.

Identity Centrality. To measure the psychological centrality of men's and women's identities, participants were then presented with a list of identities. The instructions read: "Please read the following list. For each item on this list, think of the extent to which you identify with it." The list included eight identities (friend, sibling, wife/husband, work, son/daughter, parent, national identity, religious identity) and participants could also add other identities to the list (for similar lists, see Cassidy \& Trew, 2001; McCall \& Simmons, 1978). The instructions then continued: "Please assign a percentage (from $0 \%$ to $100 \%$ ) to each of these items, in a way that reflects the extent to which each item is important for you, or represents who you are. The total must add up to $100 \%$." Cognizant of the controversy over the hierarchical nature of identities (Marks \& MacDermid, 1996), this measure allowed participants to express the equal importance of two or more identities by allocating them equal percentages. The percentages allocated to parental and work identities were then coded to obtain participants' psychological centrality scores. The Pearson intercorrelations between identity centrality and salience were .20 and .41 , for parental and work identities, respectively. This confirms that the two measures reflect relatively independent aspects of the self-structure.

Social Structural Characteristics. Participants indicated the number of children in the household and the age and gender of each child. Participants' individual annual income was measured on a 9-point scale ranging from 1 (less than $£ 7,000$ ) to 9 (more than £52,000). Participants also reported their level of education, weekly work hours, ethnic background, religiosity level, and age. Because of the potential associations between participants' age and gender attitudes (e.g., Scott, Alwin, \& Braun, 1996), preliminary analyses were 
conducted with husbands' and wives' age as covariates. These analyses did not reveal any effects for age or interactions between age and gender, and this variable was therefore not included in the final analyses.

\section{Procedure}

Participants were personally approached by a female research assistant. The study was introduced as a questionnaire survey on work and family. Fully $96 \%$ of those approached to participate and who were eligible agreed to take part in the study. After receiving both parents' agreement to participate, the research assistant obtained written consents and administered the self-report questionnaires. The questionnaires included measures of participants' identities and sociostructural characteristics, as well as measures of the division of housework and child care that extend beyond the scope of the present study. Completion of the questionnaire took approximately 30 minutes and spouses were not allowed to consult each other when filling it out. In two cases, the questionnaire was only filled out by one spouse, and that couple's data were therefore eliminated from the sample. Other missing data were subjected to listwise deletion.

\section{Results}

\section{Gender Differences and Moderation by Paid-Work Strategy}

Our first hypothesis suggested that overall, women would have more salient and central parental identities than men, and men would have more salient and central work identities than women. Gender differences in identities were examined using a 2 (Gender) $\times 4$ (Identities: centrality/salience of parental/ work identity) multivariance analysis of variance (see Table 2). This analysis revealed a significant Gender $\times$ Identity interaction, $F(3,124)=5.43$, $p=.002$. In line with Hypothesis 1a, women had more central parental identities than men, $F(1,126)=4.31, p<.001$, and a small but significant difference in the salience of parental identity was also found, $F(1,126)=3.69, p<$ .001 . The results further indicate that men had more central work-related identities than women, $F(1,126)=2.51, p=.013$, but the gender difference in work identity salience was not significant.

Our second hypothesis suggested that couples' paid-work strategy would moderate these gender differences in identities (Hypothesis $1 \mathrm{~b}$ ). To test this hypothesis, a series of 2 (Gender) $\times 3$ (Paid-Work Strategy) mixed-model analyses of variance (ANOVAs; with gender as the within-couple factor) was conducted on participants' parental and work identity salience and centrality. 
Table 2. Means, Standard Deviations, and Gender Differences in Parental and Work Identities.

\begin{tabular}{|c|c|c|c|c|c|}
\hline & \multicolumn{2}{|c|}{$\begin{array}{l}\text { Women } \\
(n=148)\end{array}$} & \multicolumn{2}{|c|}{$\begin{array}{c}\text { Men } \\
(n=148)\end{array}$} & \multirow[b]{2}{*}{$F(1,126)$} \\
\hline & $M$ & $S D$ & $M$ & $S D$ & \\
\hline Work identity salience & 5.30 & 3.60 & 5.88 & 3.43 & -1.42 \\
\hline Work identity centrality & 10.64 & 8.93 & 13.67 & 10.70 & $-2.53^{*}$ \\
\hline Parental identity salience & 9.69 & 0.61 & 9.34 & 0.91 & $3.49 * * *$ \\
\hline Parental identity centrality & 38.84 & 15.45 & 31.69 & 13.36 & $4.44 * * *$ \\
\hline
\end{tabular}

Note. Tests of significance were two-tailed. Work and parental identity salience scores ranged from 0 (nonsalient) to 10 (most salient); work and parental identity centrality scores ranged from 0 (noncentral) to 100 (most central).

$* p<.05 . * * * p<.001$.

Work Identities. The analysis on work identity centrality (see Figure 1) revealed a main effect of gender, $F(1,120)=5.89, p=.017$, indicating that men's work identities $(M=13.72)$ were more central than women's $(M=10.88)$. This main effect was qualified, however, by the predicted Gender $\times$ Paid-Work Strategy interaction, $F(2,120)=13.60, p<.001$. As can be seen in Figure 1, traditional husbands' work identities $(M=15.52)$ were more central than their wives' $(M=5.28), F(2,120)=5.88, p<.001$. However, there was no gender difference in work identity centrality among modified male-breadwinner couples, $M=14.70$, for men and 11.08, for women, $F(2$, $120)=1.62, n s$, and dual-earner wives had more central work identities $(M=$ 16.27) than their husbands $(M=10.93), F(2,120)=-2.98, p=.005$.

The Gender by Paid-Work Strategy mixed-model ANOVA on participants' work identity salience (see Figure 2) yielded no main effects but a significant Gender $\times$ Paid-Work Strategy interaction, $F(2,122)=8.70, p<.001$. As Figure 2 shows, traditional husbands had more salient work identities $(M=$ 6.22) than their wives $(M=3.07), F(2,122)=3.78, p<.001$, whereas no significant gender differences were found among modified male-breadwinner couples, $M=5.98$ and 6.16, for men and women, respectively, $F(2,122)$ $=0.65, n s$, or dual-earner couples, $M=6.20$ and 6.85 , for men and women, respectively, $F(2,122)=0.72, n s$.

Parental Identities. A similar analysis on participants' parental identity centrality (see Figure 3) revealed a main effect of gender, $F(1,120)=17.80$, $p<.001$, indicating that women's parental identities $(M=39.04)$ were more central than men's $(M=31.62)$. As expected, the gender difference in 


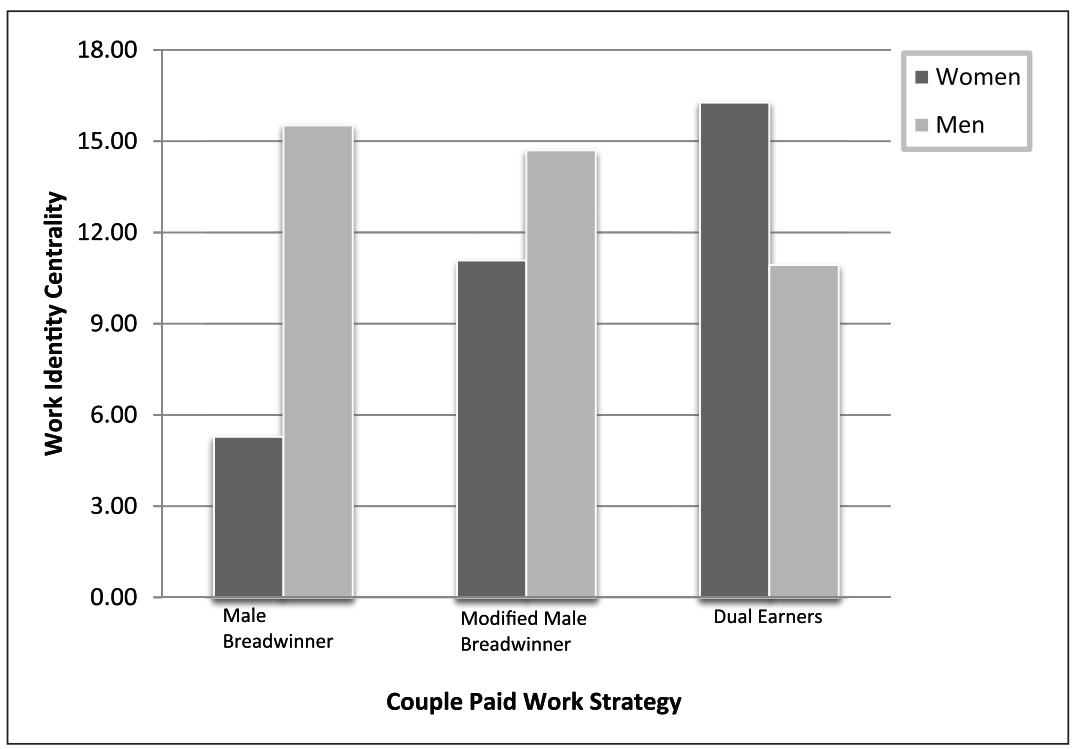

Figure I. Work identity centrality by gender and paid-work strategy.

parental identity centrality found among traditional couples, $M=42.54$, for women and $M=31.23$, for men, $F(2,120)=3.64, p<.001$, and modified male-breadwinner couples, $M=39.27$, for women and $M=30.29$, for men, $F(2,120)=2.96, p=.005$, was eliminated among dual-earner couples, $M=$ 35.30 and 33.33, for women and men, respectively, $F(2,120)=0.75$, ns. Nevertheless, the predicted Gender $\times$ Paid-Work Strategy interaction was not significant, $F(2,120)=2.29, p=.10$.

Finally, a similar pattern of results was found in the Gender by PaidWork Strategy mixed-model ANOVA on participants' parental identity salience (see Figure 4). This analysis revealed a main effect of gender, $F(1,122)=12.77, p<.001$, showing that women had more salient parental identities $(M=9.68)$ than men $(M=9.32)$. Although the predicted Gender $\times$ Paid-Work Strategy interaction was not significant, $F(2,122)=$ $2.00, n s$, the results followed the predicted pattern: The gender difference in parental identity salience found among traditional couples, $M=9.85$, for women and $M=9.21$, for men, $F(2,122)=3.27, p=.002$, and modified male-breadwinner couples, $M=9.80$, for women and $M=9.46$, for men, $F(2,122)=2.92, p=.005$, was eliminated among dual-earner couples, $M=9.41$ and 9.28 , for women and men, respectively, $F(2,122)=$ $0.51, n s$. 


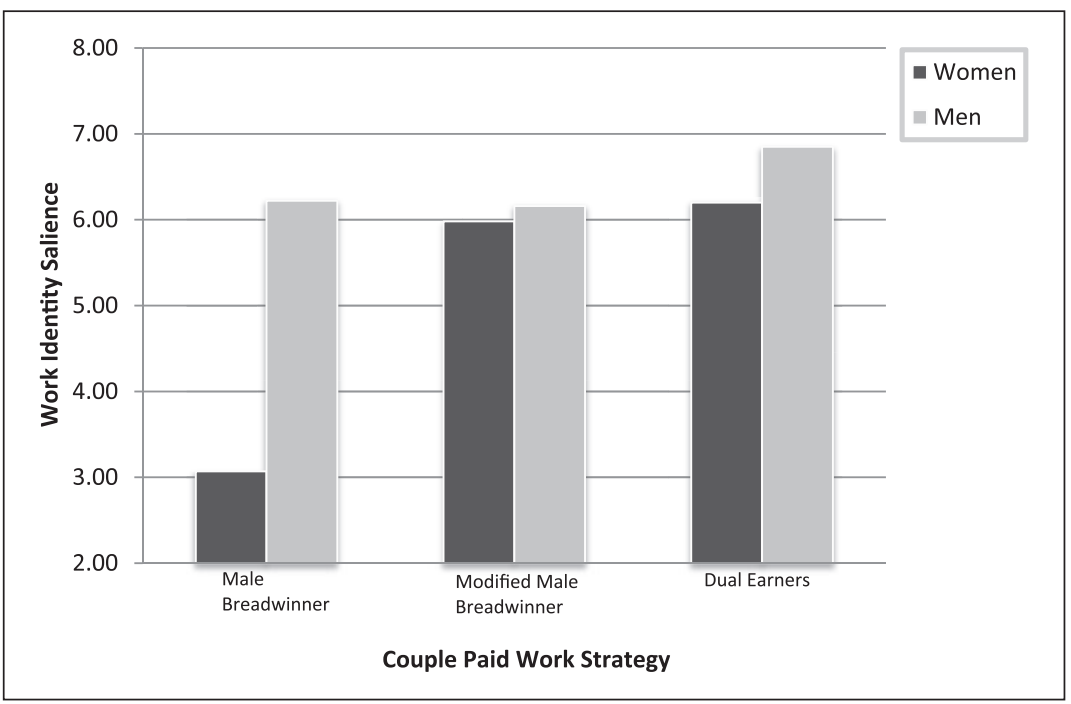

Figure 2. Work identity salience by gender and paid-work strategy.

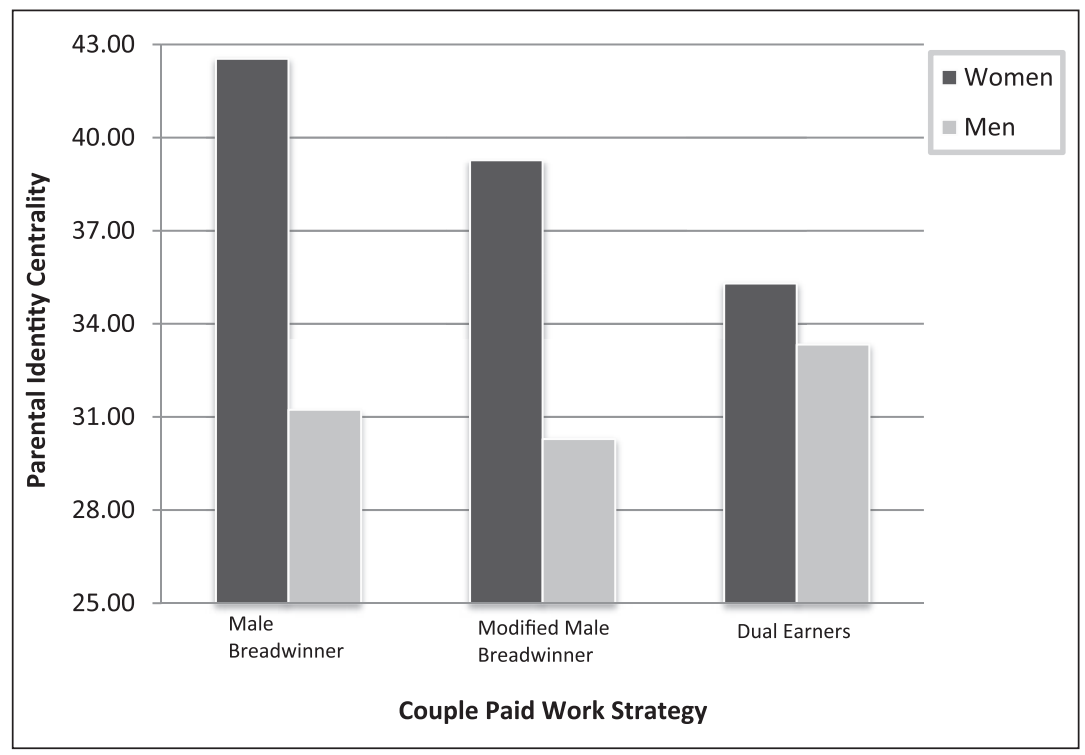

Figure 3. Parental identity centrality by gender and paid-work strategy. 


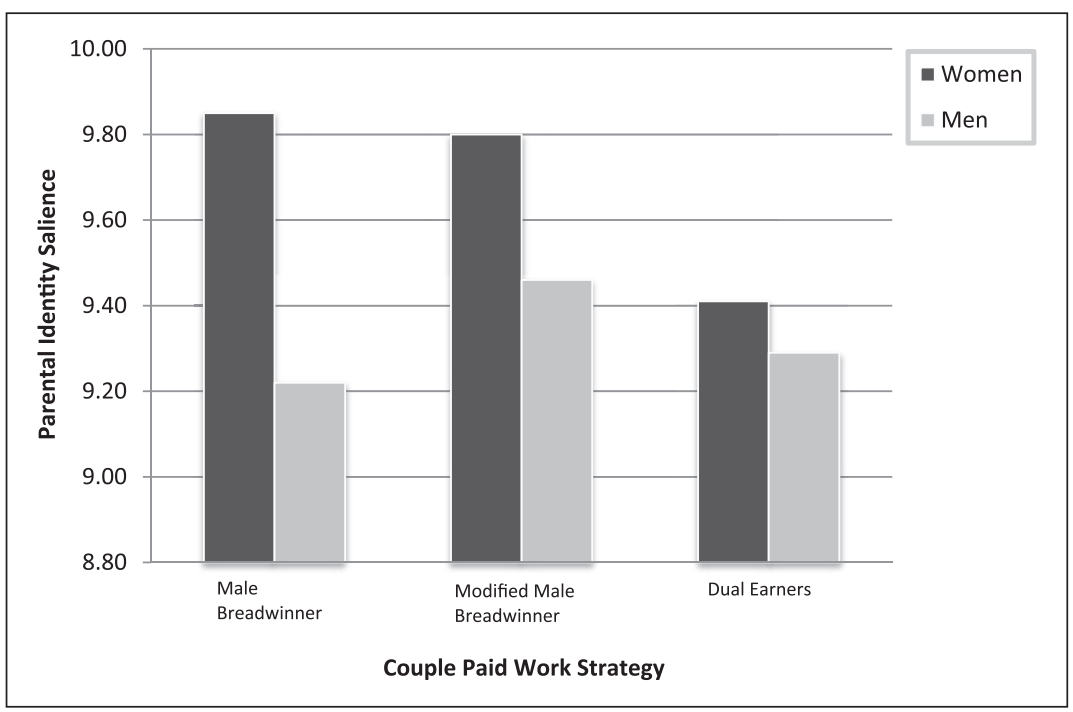

Figure 4. Parental identity salience by gender and paid-work strategy.

Overall, these results supported our prediction (Hypothesis $1 \mathrm{~b}$ ) that couple's paid-work strategy moderates gender differences in identities. As expected, the differences in identity salience and centrality found among traditional couples were eliminated among dual-earner couples.

\section{Sociostructural Characteristics and Moderation by Gender}

Our second set of hypotheses focused on the moderating role of gender in the effects of sociostructural variables on parental and work-related identities. To assess these hypotheses, we evaluated a set of simple moderation models using the PROCESS program (Model 1; Hayes, 2012, 2013) with bias-corrected bootstrap estimates and 95\% CIs. The results are presented in Table 3.

Hypothesis 2a suggested that more children and a child's younger age would have negative effects on the salience and centrality of women's work identities but not on men's work identities. The results supported this hypothesis and indicate that gender moderated the effects of the number of children and the age of the youngest child on work identity centrality. As can be seen in Figures 5 and 6, whereas the centrality of women's work identities decreased the more children they had and the younger their child, the centrality of men's work identities increased the more children they had and the younger their child. Table 3 shows that the moderating effects of gender were 


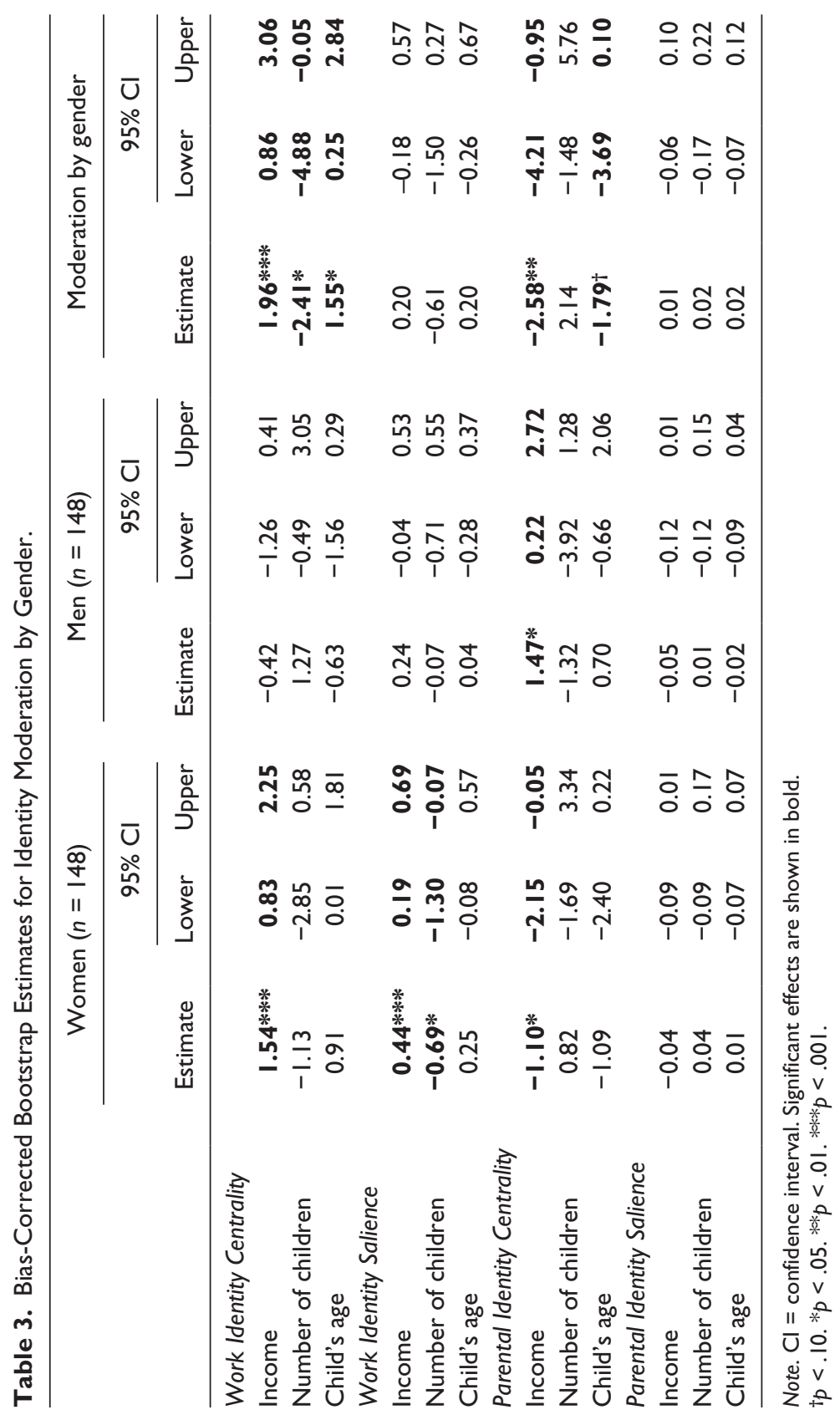




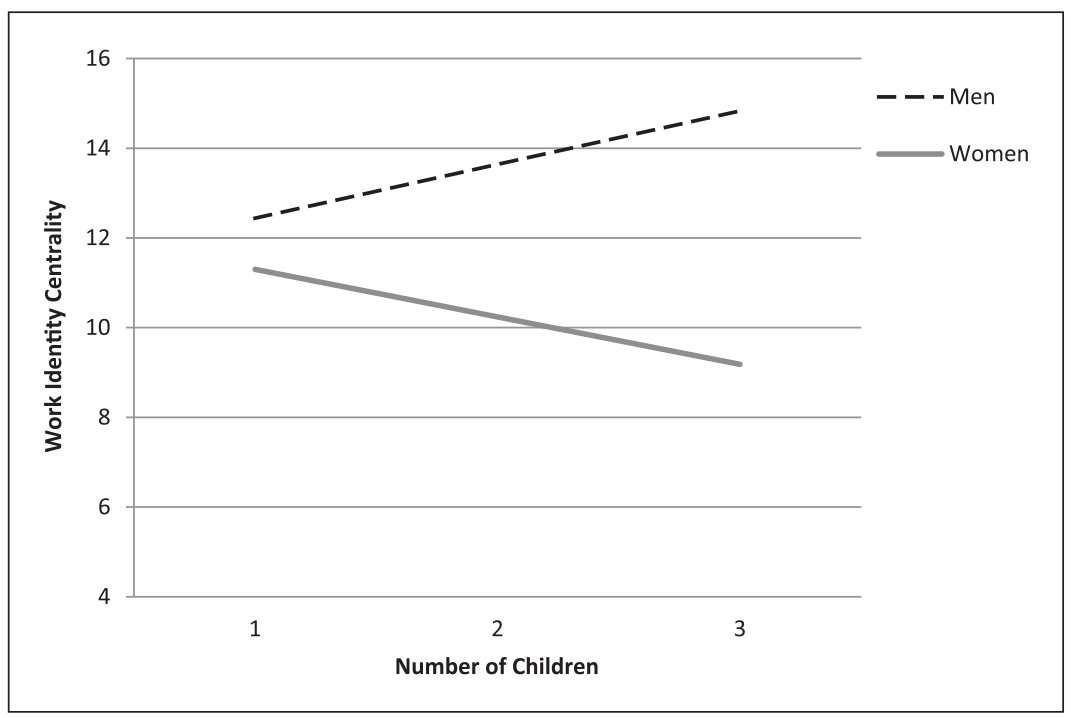

Figure 5. Work identity centrality by number of children and gender.

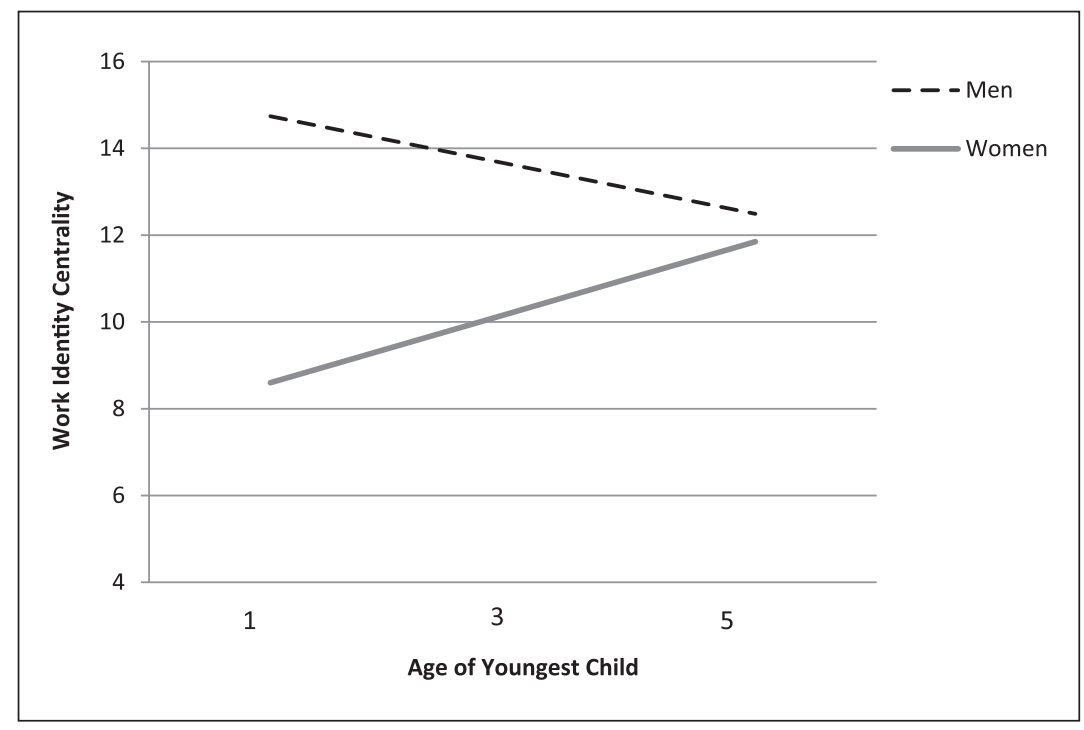

Figure 6. Work identity centrality by age of youngest child and gender. 
significant, with bootstrap CI below zero for the number of children (95\% CI $[-4.88,-0.05])$, and above zero for the age of the youngest child $(95 \% \mathrm{CI}$ $[0.25,2.84])$. Thus, although the number of children and the age of the youngest child were not significant predictors of men's and women's work identities, their associations with these identities went in opposite directions such that their disordinal interaction with gender was significant.

Hypothesis $2 \mathrm{~b}$ predicted that gender would moderate the effects of children on participants' parental identities. Specifically, it was predicted that more children and a child's younger age would be associated with more salient and central parental identities among women, but unrelated to men's parental identities. The results provided weak support for this hypothesis. As can be seen in Table 3, although gender moderation of the effect of child's age on parental identity centrality was in the expected direction, the bootstrap CI was not entirely below zero and thus only marginally significant (bootstrap $95 \%$ CI $[-3.69,0.10])$. The number of children had no effects on parental identities.

Our final hypothesis (Hypothesis 2c) suggested that gender would moderate the effects of income on participants' parental identities, such that income would be positively related to men's parental identity but negatively related to women's. Assessment of a moderation model on parental identity centrality with bias-corrected bootstrap estimates and 95\% CI confirmed this hypothesis. As can be seen in Table 3, the effects of income on both maternal and paternal identity centrality were significant, as well as the moderating effect of gender, with bootstrap CI below zero (95\% CI [-4.21, -0.95$])$. Figure 7 shows that whereas men's parental identity centrality increased with their income, women's identity centrality decreased the more they earned.

\section{Discussion}

This study sought to explore gender differences in the importance of parental and work identities and in the role played by sociostructural characteristics in shaping these identities. Given the inconsistent evidence regarding gender differences in the salience of identities (e.g., Aryee \& Luk, 1996; Friedman \& Weissbrod, 2005; Scott \& Alwin, 1989), our first goal was to consider couples' division of paid work in an attempt to clarify these inconsistencies. In line with our first set of hypotheses, the findings revealed considerable differences in the salience and centrality of both parental and work identities between stay-at-home mothers and their breadwinning husbands, whereas no differences in identities were found between spouses when both worked full time. The modified traditional couples, in which the woman worked part time, showed gender differences in parental identities but not in work 


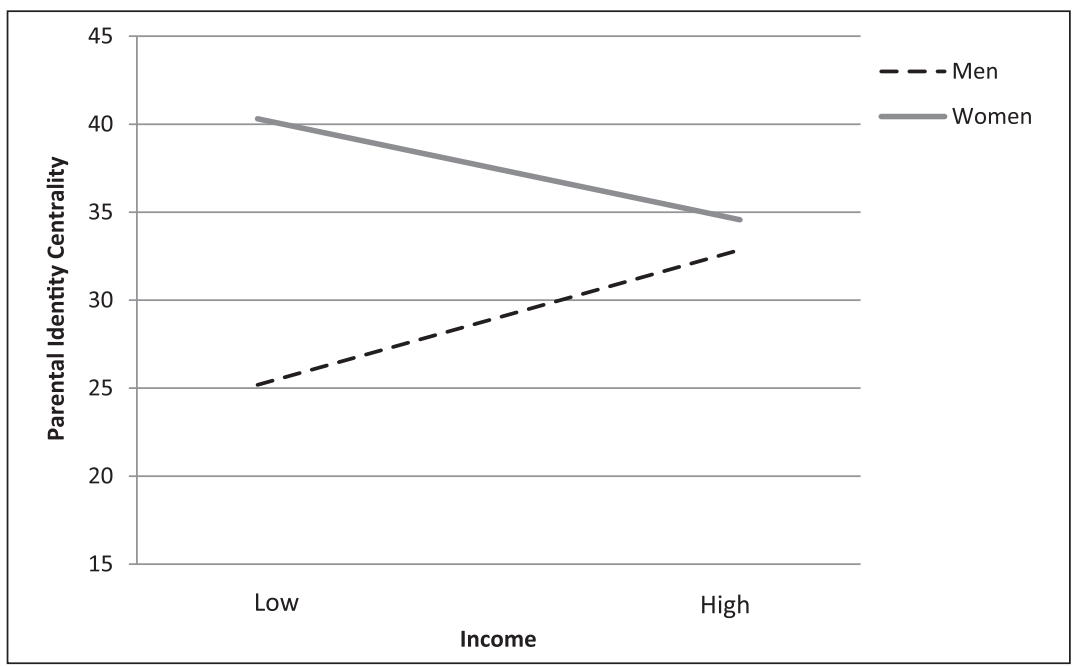

Figure 7. Parental identity centrality by income and gender.

identities. This suggests that while working part time is sufficient to enhance a woman's work identity and place it on a par with her husband's, the gap in parental identities between the spouses remains. These findings extend the literature on gender differences in identities (Aryee \& Luk, 1996; Bielby \& Bielby, 1989) and attest to the importance of couples' paid-work strategies in moderating these differences.

An interesting and unpredicted finding was that full-time working women had more central work identities than their husbands'. Full-time work is not the prevailing norm among mothers of young children and considerable societal ambivalence toward new mothers' employment still exists (Himmelweit \& Sigala, 2004; Wall, 2013). Presumably, because of the need to overcome these internal and external barriers to commit to full-time employment (e.g., Hoffnung \& Williams, 2013), women who do choose this route are characterized by particularly central professional or work-related identities.

Our second goal was to examine how sociostructural characteristics differentially affect men's and women's identities. Earlier works have discussed the different social expectations from the parental role depending on the parent's gender (DeWitt et al., 2013; Gaunt, 2013; Wiley, 1991), and showed that men's parental role is perceived as consistent with their work role, whereas women's parental and work roles are perceived as conflicting (Aryee \& Luk, 1996; Friedman \& Weissbrod, 2005; Hodges \& Park, 2013). Given that identities are internalized meanings applied to the self in a social role (Stets \& 
Serpe, 2013; Stryker, 2008), it was hypothesized that these different expectations would be reflected in differential associations between sociostructural characteristics and men's and women's identities. Overall, the findings supported this suggestion and provided evidence for the moderating role of gender in the effects of children and income on individuals' identities. In particular, it was found that men's work identity centrality increased when they had more and younger children, whereas women's work identity centrality decreased (Hypothesis 2a). Furthermore, and also as predicted (Hypothesis 2c), men's parental identity centrality increased with their income, whereas women's parental identity centrality decreased the more they earned. These two important findings clearly illustrate the notion of conflicting roles for women and consistent roles for men: Whereas men's work characteristics (i.e., income) uphold their parental identities, and family characteristics (i.e., age and number of children) uphold their work identities, the opposite is true for women.

The hypothesis concerning the stronger effects of children on women's parental identities was only weakly supported. Although the pattern of results was in the expected direction, the moderation by gender was not significant. It is possible that the limited range of children's ages in the sample masked the effects of age. That is, women's parental identities may not vary considerably when having babies and preschool children, and may show a more substantial decrease when the children enter school and become more independent.

In addition to the limited range of children's ages, the current sample included an overrepresentation of well-educated participants which may have deflated gender differences in identities. Specifically, better educated women are more likely to be employed and the gap in income between them and their husbands tends to be smaller (England, Gornick, \& Shafer, 2012). A wider representation of education levels might have revealed greater gender differences in both work identity centrality and sociostructural characteristics such as work hours and income. Additionally, the sample size prevented the inclusion of a female breadwinner category as a fourth paidwork strategy. Due to their relative rarity in the population, only nine couples in our sample represented this category. However, examining parental and work identities of breadwinning mothers and primary caregiving fathers is of major theoretical importance and could shed more light on the ways in which identities are shaped by social structures and life experiences (e.g., Doucet, 2004; Doucet \& Merla, 2007; Medved, 2009; Medved \& Rawlins, 2011). Future explorations of gender differences in identities and their correlates would therefore benefit from analyzing large representative samples of parents with wider ranges of paid-work strategies, sociodemographic backgrounds, and children's ages. 
The study benefitted from the inclusion of two distinct measures of identity importance (Stryker \& Serpe, 1994). Whereas the measure of identity centrality engaged participants in conscious deliberation about the percentages they allocated to various identities, the measure of salience via a "Who am I?" question captured the mental availability of various identities. To minimize order effects, identity salience was measured first, followed by identity centrality. Overall, the more conscious measure of identity centrality seemed more closely associated to individuals' structural variables than the relatively implicit measure of salience. The lack of significant findings linking parental identity salience to background variables, in particular, may have stemmed from the particularly small variability in this measure: Parental identity was either the first or second identity mentioned by the vast majority of women (95\%) and men (90\%) in the sample.

Finally, the cross-sectional nature of the research design precludes a determination of the direction of causal relations between identities and the sociostructural characteristics. From a theoretical perspective, insofar as individuals have control over their environment and an ability to change their circumstances, both directions of influence are plausible. That is, identity theory assumes that identities are formed within a certain array of social structures, and in turn, they guide individual behavioral choices (Gaunt \& Scott, 2014; Merolla et al., 2012; Stryker \& Burke, 2000). Thus, for example, whereas women's employment is likely to affect the importance they attach to their work identity, it is also likely that more central and salient work identity lead them to choose full-time employment. Future longitudinal investigations of these relations could help determine their causal nature and direction more accurately. Nevertheless, certain structural characteristics such as gender and socioeconomic status are less susceptible to individuals' choices and therefore enable more definite causal conclusions (Stryker et al., 2005). Thus, although people generally choose whether to have children, the age of a child at a certain point in time is beyond their control, and its links with the centrality of parental and work identities is likely to reflect its influence on these identities.

In conclusion, the findings from the current study shed light on the interactive effects of gender and other structural characteristics on parental and work identities. Taken together, the findings suggest that the overall differences between men's and women's identities and their correlates are attenuated among spouses with more similar life circumstances. That is, differences in the salience and centrality of parental and work identities tend to disappear when both spouses work full time and as their children grow older. These findings attest to the importance of examining differences within as well as between genders, by taking interactions between gender, parenting, and 
employment into account. Continuing societal change toward greater gender equality (Deutsch, 2007; Sullivan, 2006) may be reflected in a gradual decrease in the moderating role of gender in future research.

\section{Declaration of Conflicting Interests}

The author(s) declared no potential conflicts of interest with respect to the research, authorship, and/or publication of this article.

\section{Funding}

The author(s) disclosed receipt of the following financial support for the research, authorship, and/or publication of this article: The research leading to these results received funding from the European Union Seventh Framework Programme (FP7/20072013) under grant agreement no 253022.

\section{References}

Adams, M., Walker, C., \& O'Connell, P. (2011). Invisible or involved fathers? A content analysis of representations of parenting in young children's picturebooks in the UK. Sex Roles, 65, 259-270. doi:10.1007/s11199-011-0011-8

Aryee, S., \& Luk, V. (1996). Balancing two major parts of adult life experience: Work and family identity among dual-earner couples. Human Relations, 49, 465-487. doi:10.1177/001872679604900404

Baxter, J., Hewitt, B., \& Haynes, M. (2008). Life course transitions and housework: Marriage, parenthood, and time on housework. Journal of Marriage and Family, 70, 259-272. doi:10.1111/j.1741-3737.2008.00479.x

Bianchi, S. M., \& Milkie, M. A. (2010). Work and family research in the first decade of the 21st century. Journal of Marriage and Family, 72, 705-725. doi:10.1111/ j.1741-3737.2010.00726.x

Bielby, W. T., \& Bielby, D. D. (1989). Family ties: Balancing commitments to work and family in dual earner households. American Sociological Review, 54, 776-789.

Burke, P. J., \& Stets, J. E. (2009). Identity theory. New York, NY: Oxford University Press.

Cassidy, C., \& Trew, K. (2001). Assessing identity change: A longitudinal study of transition from school to college. Group Processes \& Intergroup Relations, 3, 49-60. doi:10.1177/1368430201041004

Cinamon, R. G., \& Rich, Y. (2002). Gender differences in the importance of work and family roles: Implications for work-family conflict. Sex Roles, 47, 531-541. doi:10.1023/A:1022021804846

Deutsch, F. M. (2007). Undoing gender. Gender \& Society, 21, 106-127. doi:10.1177/ 0891243206293577

DeWitt, A. L., Cready, C. M., \& Seward, R. R. (2013). Parental role portrayals in twentieth century children's picture books: More egalitarian or ongoing stereotyping? Sex Roles, 69, 89-106. doi:10.1007/s11199-013-0285-0 
Dhawan, N., Roseman, I. J., Naidu, R. K., Thapa, K., \& Rettek, S. I. (1995). Selfconcepts across two cultures: India and the United States. Journal of CrossCultural Psychology, 26, 606-621. doi:10.1177/002202219502600606

Doucet, A. (2004). "It's almost like I have a job, but I don't get paid": Fathers at home reconfiguring work, care, and masculinity. Fathering, 2, 277-303.

Doucet, A., \& Merla, L. (2007). Stay-at-home fathering: A strategy for balancing work and home in Canadian and Belgian families. Community, Work \& Family, $10,455-473$.

Eaton, L., \& Louw, J. (2000). Culture and self in South Africa: Individualismcollectivism predictions. Journal of Social Psychology, 140, 210-217. doi:10.1080/ 00224540009600461

England, P., Gornick, J., \& Shafer, E. F. (2012). Women's employment, education, and the gender gap in 17 countries. Monthly Labor Review, 135, 3-12.

Evertsson, M. (2013). The importance of work: Changing work commitment following the transition to motherhood. Acta Sociologica, 56, 139-153. doi:10.1177/ 0001699312466177

Fox, G. L., \& Bruce, C. (2001). Conditional fatherhood: Identity theory and parental investment theory as alternative sources of explanation of fathering. Journal of Marriage and Family, 63, 394-403.

Friedman, S. R., \& Weissbrod, C. S. (2005). Work and family commitment and decision-making status among emerging adults. Sex Roles, 53, 317-325. doi:10.1007/s11199-005-6755-2

Gaunt, R. (2013). Breadwinning moms, caregiving dads: Double standard in social judgments of gender norm violators. Journal of Family Issues, 34, 3-24. doi:10. $1177 / 0192513 X 12438686$

Gaunt, R., \& Benjamin, O. (2007). Job insecurity, stress and gender: The moderating role of gender ideology. Community, Work \& Family, 10, 341-355. doi:10.1080/13668800701456336

Gaunt, R., \& Scott, J. (2014). Parents' involvement in childcare: Do parental and work identities matter? Psychology of Women Quarterly, 38, 475-489. doi:10.1177/0361684314533484

Gershuny, J. (2004). Time, through the life course, in the family. In J. Scott, J. Treas, \& M. Richards (Eds.), The Blackwell companion to the sociology of families (pp. 158-173). Malden, MA: Blackwell.

Goldberg, J. S. (2015). Identity and involvement among resident and nonresident fathers. Journal of Family Issues, 36, 852-879. doi:10.1177/01925 $13 \mathrm{X} 13500963$

Gregory, A., \& Milner, S. (2011). What is "new" about fatherhood? The social construction of fatherhood in France and the UK. Men and Masculinities, 14, 588606. doi:10.1177/1097184X11412940

Harkness, S. (2008). The household division of labour: Changes in families' allocation of paid and unpaid work. In J. Scott, S. Dex, \& H. Joshi (Eds.), Women and employment: Changing lives and new challenges (pp. 234-267). Gloucester, England: Edward Elgar. 
Hayes, A. F. (2012). PROCESS: A versatile computational tool for observed variable mediation, moderation, and conditional process modeling (White paper). Retrieved from http://www.afhayes.com/

Hayes, A. F. (2013). Introduction to mediation, moderation, and conditional process analysis. New York, NY: Guilford Press.

Himmelweit, S., \& Sigala, M. (2004). Choice and relationship between identities and behaviour for mothers with pre-school children: Some implications for policy from a UK study. Journal of Social Policy, 33, 455-478. doi:10.1017/ S0047279404007779

Hodges, A. J., \& Park, B. (2013). Oppositional identities: Dissimilarities in how women and men experience parent versus professional roles. Journal of Personality and Social Psychology, 105, 193-216. doi:10.1037/a0032681

Hoffnung, M., \& Williams, M. A. (2013). Balancing act: Career and family during college-educated women's 30s. Sex Roles, 68, 321-334. doi:10.1007/s11199012.0248.x

Kan, M. Y., Sullivan, O., \& Gershuny, J. (2011). Gender convergence in domestic work: Discerning the effects of interactional and institutional barriers from largescale data. Sociology, 45, 234-251. doi:10.1177/0038038510394014

Kanagawa, C., Cross, S. E., \& Markus, H. R. (2001). "Who am I?" The cultural psychology of the conceptual self. Personality and Social Psychology Bulletin, 27, 90-103. doi:10.1177/0146167201271008

Kanji, S. (2011). What keeps mothers in full-time employment? European Sociological Review, 27, 509-525. doi:10.1093/esr/jcq022

Katz-Wise, S. L., Priess, H. A., \& Hyde, J. S. (2010). Gender-role attitudes and behavior across the transition to parenthood. Developmental Psychology, 46, 1928. doi:10.1037/a0017820

Kuhn, M. H., \& McPartland, T. S. (1954). An empirical investigation of self-attitudes. American Sociological Review, 19(1), 68-76.

Lay, C., \& Verkuyten, M. (1999). Ethnic identity and its relation to personal selfesteem: A comparison of Canadian-born and foreign-born Chinese adolescents. Journal of Social Psychology, 139, 288-299.

Mackie, M. (1983). The domestication of self: Gender comparisons of self-imagery and self-esteem. Social Psychology Quarterly, 46, 343-350.

Marks, S. R., \& MacDermid, S. M. (1996). Multiple roles and the self: A theory of role balance. Journal of Marriage and the Family, 58, 417-432.

Maurer, T. W., Pleck, J. H., \& Rane, T. R. (2001). Parental identity and reflectedappraisals: Measurement and gender dynamics. Journal of Marriage and Family, 63, 309-321. doi:10.1111/j.1741-3737.2001.00309.x

McCall, G. J., \& Simmons, J. L. (1978). Identities and interactions: An examination of human associations in everyday life. New York, NY: Free Press.

McGill, B. S. (2014). Navigating new norms of involved fatherhood: Employment, fathering attitudes, and father involvement. Journal of Family Issues, 35, 10891106. doi:10.1177/0192513X14522247.

Medved, C. E. (2009). Constructing breadwinning-mother identities: Moral, personal, and political positioning. Women's Studies Quarterly, 37(3-4), 140-156. 
Medved, C. E., \& Rawlins, W. K. (2011). At-home fathers and breadwinning mothers: Variations in constructing work and family lives. Women and Language, 34(2), 9-39.

Merolla, D. M., Serpe, R. T., Stryker, S., \& Schultz, P. W. (2012). Structural precursors to identity processes: The role of proximate social structures. Social Psychology Quarterly, 75, 149-172. doi:10.1177/0190272511436352

Mussweiler, T., \& Bodenhausen, G. V. (2002). I know you are, but what am I? Selfevaluative consequences of judging in-group and out-group members. Journal of Personality and Social Psychology, 82, 19-32. doi:10.1037/0022-3514.82.1.19

Office for National Statistics. (2008). Work and family. Retrieved from http://www. statistics.gov.uk/cci/nugget.asp?id=1655.

Office for National Statistics. (2011). Education and training. Social Trends, 41. Retrieved from http://www.ons.gov.uk/ons/rel/social-trends-rd/social-trends/socialtrends-41/index.html

Rentsch, J. R., \& Heffner, T. S. (1992). Measuring self-esteem: Validation of a new scoring technique for "Who Am I?" responses. Educational and Psychological Measurement, 52, 641-651. doi:10.1177/0013164492052003013

Rosenberg, M. (1979). Conceiving the self. New York, NY: Basic Books.

Sayer, L. C., \& Gornick, J. C. (2011). Cross-national variation in the influence of employment hours on childcare time. European Sociological Review, 28, 421-442. doi:10.1093/esr/jcr008

Scott, J., \& Alwin, D. F. (1989). Gender differences in parental strain: Parental role or gender role? Journal of Family Issues, 10, 482-503. doi:10.1177/ 019251389010004004

Scott, J., Alwin, D. F., \& Braun, M. (1996). Generational changes in gender-role attitudes: Britain in a cross-national perspective. Sociology, 30, 471-492. doi:10.1177/0038038596030003004

Scott, J., Dex, S., \& Joshi, H. (Eds.). (2008). Women and employment: Changing lives and new challenges. Gloucester, England: Edward Elgar.

Scott, J., Dex, S., \& Plagnol, A. C. (Eds.). (2012). Gendered lives: Gender inequalities in production and reproduction. Gloucester, England: Edward Elgar.

Scott, J., \& Plagnol, A. C. (2012). Work-family conflict and well-being in northern Europe. In J. Scott, S. Dex, \& A. C. Plagnol (Eds.), Gendered lives: Gender inequalities in production and reproduction (pp. 174-205). Gloucester, England: Edward Elgar.

Snir, R., Harpaz, I., \& Ben-Baruch, D. (2009). Centrality of and investment in work and family among Israeli high-tech workers: A bicultural perspective. CrossCultural Research, 43, 366-385. doi:10.1177/1069397109336991

Stets, J. E., \& Biga, C. F. (2003). Bringing identity theory into environmental sociology. Sociological Theory, 21, 398-423. doi:10.1046/j.1467-9558.2003.00196.x

Stets, J. E., \& Serpe, R. T. (2013). Identity theory. In J. DeLamater \& A. Ward (Eds.), Handbook of social psychology (pp. 31-60). New York, NY: Springer.

Stone, P. (2007). Opting out? Why women really quit careers and head home. Berkeley: University of California Press. 
Stryker, S. (1980). Symbolic interactionism: A social structural version. Menlo Park, CA: Benjamin/Cummings.

Stryker, S. (1987). Identity theory: Developments and extensions. In K. Yardley \& T. Honess (Eds.), Self and identity (pp. 89-104). New York, NY: Wiley.

Stryker, S. (2008). From Mead to a structural symbolic interactionism and beyond. Annual Review of Sociology, 34, 15-31. doi:10.1146/annurev.soc.34.040507.134649

Stryker, S., \& Burke, J. (2000). The past, present, and future of an identity theory. Social Psychology Quarterly, 63, 284-297.

Stryker, S., \& Serpe, R. T. (1994). Identity salience and psychological centrality: Equivalent, overlapping or complementary concepts? Social Psychology Quarterly, 57, 16-34.

Stryker, S., Serpe, R. T., \& Hunt, M. O. (2005). Making good on a promise: The impact of larger social structures on commitments. Advances in Group Processes, 22, 93-123. doi:10.1016/S0882-6145(05)22004-0

Sullivan, O. (2006). Changing gender relations, changing families: Tracing the pace of change over time. Lanham, MD: Rowman \& Littlefield.

Thoits, P. A. (1991). On merging identity theory and stress research. Social Psychology Quarterly, 54, 101-112.

Thoits, P. A. (1992). Identity structures and psychological well-being: Gender and marital status comparisons. Social Psychology Quarterly, 55, 236-256.

Wall, G. (2013). "Putting family first": Shifting discourses of motherhood and childhood in representations of mothers' employment and child care. Women's Studies International Forum, 40, 162-171. doi:10.1016/j.wsif.2013.07.006

Wall, G., \& Arnold, S. (2007). How involved is involved fathering? An exploration of the contemporary culture of fatherhood. Gender \& Society, 21, 508-527. doi: $10.1177 / 0891243207304973$

Wiley, M. G. (1991). Gender, work, and stress: The potential impact of role-identity salience and commitment. Sociological Quarterly, 32, 495-510. 